Research Article

\title{
Experience with Renal Autotransplantation: Typical and Atypical Indications
}

\author{
Ali Bourgi (iD, Rana Aoun, Elias Ayoub, and Maroun Moukarzel \\ Department of Urology, Hotel-Dieu de France University Hospital, Boulevard Alfred Naccache, Achrafieh, P.O. Box 166830, \\ Beirut, Lebanon \\ Correspondence should be addressed to Ali Bourgi; alibourgi@gmail.com
}

Received 1 November 2017; Revised 18 February 2018; Accepted 21 February 2018; Published 26 March 2018

Academic Editor: Miroslav Djordjevic

Copyright (c) 2018 Ali Bourgi et al. This is an open access article distributed under the Creative Commons Attribution License, which permits unrestricted use, distribution, and reproduction in any medium, provided the original work is properly cited.

Introduction and Objectives. Renal autotransplantation is a kidney-saving surgical procedure used in selected patients. The purpose of this report is to review nine typical and atypical indications for kidney autotransplantation and evaluate its effectiveness in maintaining kidney function and avoiding cancer recurrence. Materials and Methods. From 1999 till 2014, nine renal autotransplantations were performed in our center. A retrospective case review was done. Four of nine patients had a solitary functioning kidney. Typical indications for autotransplantation included extended ureteric disease in 5 patients, intrasinusal tumor on a solitary kidney in 1 patient, and renal artery aneurysm in 1 patient. Atypical indications consisted in bilateral urothelial tumors in 1 patient and interrupted live kidney transplantation in 1 patient. Mean cold ischemia time was 209 minutes. Demographic factors, indications, renal function before and after surgery, and in the long term, cancer recurrence and disease-free survival were evaluated. Results. Renal function was maintained in 8 patients during the early follow-up. No serious complications occurred in the postoperative period. Median duration of follow-up was 50 months. In 4 patients with a normal contralateral kidney, mean preoperative and at discharge creatinine clearance were $105.45 \mathrm{ml} / \mathrm{min}$ and $121.02 \mathrm{ml} / \mathrm{min}$, respectively. Although values showed an improvement in the kidney function, the difference was not significant ( $p$ value 0.3 ). In the other 4 patients with a solitary kidney, mean discharge creatinine clearance was $99.24 \mathrm{ml} / \mathrm{min}$ surprisingly higher than the preoperative value $96.92 \mathrm{ml} / \mathrm{min}$. At the last follow-up, kidney function was preserved for the two groups (normal contralateral kidney/solitary kidney) with relatively stable creatinine clearance values: $108.45 \mathrm{ml} / \mathrm{min}$ and $85.9 \mathrm{ml} / \mathrm{min}$, respectively. No patients required secondary dialysis. Conclusion. Renal autotransplantation is a rare, safe, and effective surgical procedure for the treatment of complex urologic conditions. In some instances, it may be of great utility for kidney salvage in some carefully selected patients.

\section{Introduction}

Renal autotransplantation (RA) is a rare, safe, and effective surgical procedure for the treatment of complex urologic conditions. It was first reported by J. D. Hardy in 1963 when he repaired a high ureteric injury following aortic surgery by reimplanting the repaired organ into the ipsilateral iliac fossa.

Hardy's accomplishment was made possible, thanks to allotransplantation techniques developed by Dr Murray and colleagues in Boston a decade earlier. Managing renal disease via a "benchwork" approach soon became a novel idea pursued worldwide by surgeons [1].

After this landmark surgery, RA has been steadily improved to a safe and effective procedure and has been used in the treatment of different complex urologic diseases like extensive ureteric injuries, complex nephrolithiasis, loinpain syndrome, renovascular diseases (stenotic lesions of distal renal arteries, intrarenal aneurysms, and arteriovenous malformations), tumors of the kidney and ureter, and retroperitoneal fibrosis [2], even more in rare and unusual critical situations.

As minimal invasive surgery has started to take the lead, decrease in surgical morbidity is now seen with laparoscopic and even completely intracorporeal robotic surgery [3].

The purpose of this report is to present nine typical and atypical indications for kidney autotransplantation in order to evaluate its effectiveness in maintaining kidney function and avoiding cancer recurrence and to review the current literature. 
TABLe 1: Demographic and preoperative data in study population.

\begin{tabular}{|c|c|c|c|c|c|}
\hline Patient & Age & Sex & $\begin{array}{c}\text { BMI } \\
\left(\mathrm{kg} / \mathrm{m}^{2}\right)\end{array}$ & Indication for autotransplantation & Contralateral kidney \\
\hline 1 & 42 & M & 27.42 & Extended left ureteral injury & \multirow{2}{*}{$\begin{array}{c}\text { Right kidney agenesis } \\
\text { Nonfunctioning right kidney due to neglected } \\
\text { ureteropelvic junction }\end{array}$} \\
\hline 2 & 52 & $\mathrm{~F}$ & 27.34 & Extended left ureteral injury & \\
\hline 3 & 60 & $\mathrm{~F}$ & 22.8 & \multirow{3}{*}{$\begin{array}{c}\text { Interrupted living kidney donor due to } \\
\text { perioperative cardiac failure in the recipient } \\
5.5 \text { right hilum tumor (ex vivo repair) } \\
\text { Right ureter fibrosis after radiotherapy for prostate } \\
\text { cancer }\end{array}$} & Normal \\
\hline 4 & 60 & M & 33.4 & & Left nephrectomy for familial living donor \\
\hline 5 & 61 & $\mathrm{M}$ & 31.31 & & Chronic renal failure \\
\hline 6 & 32 & $\mathrm{~F}$ & 21.48 & Left ureteral injury (stripping during ureteroscopy) & \\
\hline 7 & 38 & $\mathrm{~F}$ & 21.03 & Right $\epsilon$ & Normal \\
\hline 8 & 38 & $\mathrm{~F}$ & 22.58 & Left renal artery aneurysm (ex vivo repair) & \multirow{2}{*}{$\begin{array}{l}\text { Normal } \\
\text { Nephroureterectomy for right ureteral and pelvic } \\
\text { tumor }\end{array}$} \\
\hline 9 & 65 & M & 20.28 & Bilateral ureteral and pelvic tumor & \\
\hline
\end{tabular}

TABle 2: Perioperative and postoperative parameters.

\begin{tabular}{|c|c|c|c|c|c|c|c|c|c|}
\hline & $\begin{array}{c}\text { Patient } \\
1 \\
\end{array}$ & $\begin{array}{l}\text { Patient } \\
2 \\
\end{array}$ & $\begin{array}{c}\text { Patient } \\
3 \\
\end{array}$ & $\begin{array}{c}\text { Patient } \\
4 \\
\end{array}$ & $\begin{array}{c}\text { Patient } \\
5 \\
\end{array}$ & $\begin{array}{c}\text { Patient } \\
6 \\
\end{array}$ & $\begin{array}{l}\text { Patient } \\
7 \\
\end{array}$ & $\begin{array}{c}\text { Patient } \\
8\end{array}$ & $\begin{array}{c}\text { Patient } \\
9\end{array}$ \\
\hline Operating time (hours) & 8 & 8 & 6.5 & 8.5 & 10 & 9 & 6 & 7.5 & 11 \\
\hline Duration of ischemia (min) & 70 & 180 & 215 & 270 & 230 & 230 & 145 & 240 & 300 \\
\hline Duration of hospitalization (days) & 17 & 8 & 7 & 16 & 12 & 18 & 9 & 7 & 14 \\
\hline Pre-op creatinine clearance $(\mathrm{ml} / \mathrm{min})$ & 139.77 & 108.54 & 113.33 & 79.37 & 60.03 & 57.01 & 106.1 & 145.3 & 59.5 \\
\hline Creatinine clearance at discharge $(\mathrm{ml} / \mathrm{min})$ & 157.27 & 109.4 & 123.19 & 40.26 & 90.04 & 76.69 & 153.2 & 131 & 23.6 \\
\hline Duration of follow-up (months) & 120 & 6 & 12 & 60 & 24 & 72 & 24 & 120 & 48 \\
\hline $\begin{array}{l}\text { Creatinine clearance at the last follow-up } \\
(\mathrm{ml} / \mathrm{min})\end{array}$ & 154.29 & 91.52 & 107.24 & 61.6 & 36.21 & 72.68 & 127.78 & 126.1 & 41.93 \\
\hline
\end{tabular}

\section{Materials and Methods}

From 1999 till 2014, nine renal autotransplantations were performed in our center (Hotel Dieu de France University Hospital). A retrospective case review was done. The series included five females and four males with a mean age of 49.8 years. 4/9 patients had a solitary functioning kidney. Typical indications for autotransplantation included extended ureteric disease in 5 patients, intrasinusal tumor on a solitary kidney in 1 patient, and renal artery aneurysm in 1 patient. Atypical indications consisted in bilateral urothelial tumors in 1 patient and interrupted live kidney transplantation in 1 patient.

The kidneys were removed through a flank incision over the 11th rib or laparoscopically and transplanted to the iliac fossa. In all patients, the ureter was reimplanted in the bladder using the Lich-Gregoir technique. Mean cold ischemia time was 209 minutes.

Demographic factors, indications, renal function before and after surgery, and in the long term, cancer recurrence and disease-free survival were evaluated (Tables 1-3).

\section{Results}

Renal function was evaluated by creatinine clearance estimate using the Cockcroft-Gault equation. This was maintained in 8 patients during the early follow-up (Figure 1).

No serious complications occurred in the postoperative period. Median duration of follow-up was 50 months. In 4 patients with a normal contralateral kidney, mean preoperative and at discharge creatinine clearance were $105.45 \mathrm{ml} / \mathrm{min}$ and $121.02 \mathrm{ml} / \mathrm{min}$, respectively. Although values showed an improvement in the kidney function, the difference was not deemed significant ( $p$ value 0.3 ).

In the other 4 patients with a solitary kidney, mean discharge creatinine clearance was $99.24 \mathrm{ml} / \mathrm{min}$ surprisingly higher than the preoperative value $96.92 \mathrm{ml} / \mathrm{min}$. Note that the difference between these means was not significant ( $p$ value 0.72 ). At the last follow-up, kidney function was preserved for the two groups (normal contralateral kidney/solitary kidney) with relatively stable creatinine clearance values: $108.45 \mathrm{ml} / \mathrm{min}$ and $85.9 \mathrm{ml} / \mathrm{min}$, respectively. No patients required secondary dialysis. The patient with bilateral pelvic and ureteric tumors is still cancer free, 7 years after surgery, with no recurrence on the annual CT scan. Finally, the patient with solitary kidney and intrasinusal tumor is also cancer free after 10 years of follow-up.

\section{Discussion}

The main reason for the use of kidney autotransplantation is to preserve renal parenchyma. RA is generally reserved to severe situations and is often the last option before nephrectomy. Previous studies have emphasized AR as a highly effective surgical procedure for the treatment of renal pathologies.

The most common indications of RA are the extensive ureteral lesions. In fact, it allows a direct pelvivesical anastomosis. Indeed RA is a viable option for complicated ureteral lesions and 
TABLE 3: Perioperative and postoperative complications.

\begin{tabular}{lc}
\hline Patient & Complications \\
\hline 1 & Immediate renal artery thrombosis necessitating \\
& retransplantation of the kidney in the contralateral \\
2 & iliac fossa \\
3 & Urinary infection \\
4 & None \\
5 & Acute tubular necrosis, pneumonia \\
6 & Intestinal occlusion medically resolved \\
7 & Urinary infection \\
8 & None \\
9 & Urinary infection \\
\hline
\end{tabular}

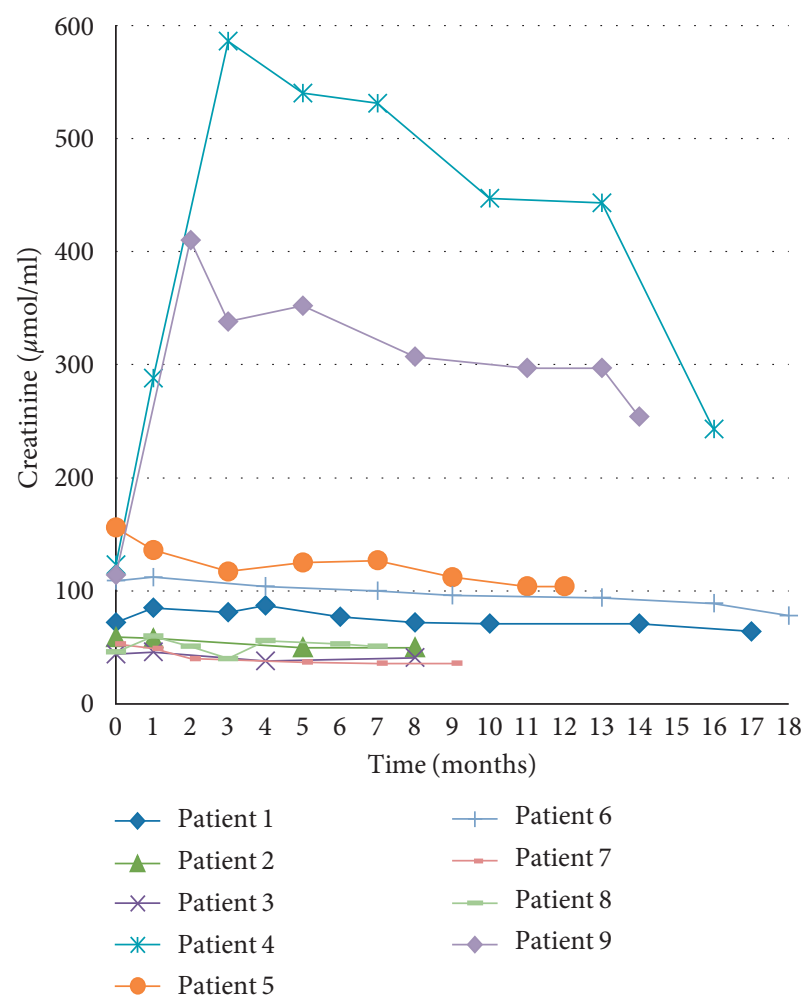

FIGURE 1: Early outcome: renal function.

is an alternative to known methods not limited to psoas Hitch procedure, Boari flap, and transureteroureterostomy [4].

In the oncological setting, no study aimed at comparing the oncological outcome after autotransplantation versus radical surgery, but in most published papers, low recurrence rate and few complications were reported with autotransplantation in patients with renal or ureteral tumors.

The first paper was published in 1984 by Pettersson et al. [4] who performed nephroureterectomy, renal autotransplantation, and pyelocystostomy in eight patients with upper urinary tract urothelial carcinoma. Five of eight patients remained cancer free after 32 months of follow-up. Radical surgery had to be done in one patient after 4.5 years because of infiltrating tumor recurrence, and transurethral endoscopic resection was done successfully in three patients with calyceal recurrence. Pettersson et al. concluded that this procedure implies increased radicality compared with conventional conservative treatment and simplified follow-up. It may be considered in patients with bilateral tumors or tumors of a solitary kidney and in selected patients with unilateral low-grade, low-stage tumors [5].

The longest follow-up was reported by Holmang and Johansson in 2005 [6]. His study was conducted on 23 patients with urothelial neoplasm in the upper urinary tract, operated with resection and autotransplantation than followed for 7 to 20 years. Of the nine patients who had solitary kidney or bilateral tumors, three patients survived with no recurrences and no dialysis after 238 and 127 months, respectively, three patients required dialysis 2 to 9 years later, and 3 patients died of the disease. Concerning patients with normal contralateral kidney, Holmang and Johansson argued that resection and renal autotransplantation are not indicated and might even be harmful, compared to standard nephroureterectomy [6].

Ex vivo nephron-sparing surgery for renal carcinoma is also an option in solitary kidney or in bilateral tumors.

The term "bench surgery" is used to describe reconstructive surgery on diseased kidneys receiving asanguineous perfusion outside the body. The first uses of bench surgery were reported by Corman et al. in 1973. Their report and subsequent ones about bench surgery have shown how this sophisticated approach is a significant advance in urologic operative procedures.

In their report, Putnam et al. [7] reported two uses of bench surgery (staghorn calculi in a solitary kidney and abdominal aortic aneurysm with abnormalities of both renal arteries and early renal failure).

One study published in 1985 by Mayo Clinic showed similar rates of nonprogression (76\%) and survival (87\%) in patients with low-grade (1 or 2), low-stage (I or II), bilateral or solitary renal cell carcinoma treated with conservative surgical treatment (in situ enucleation, in situ partial nephrectomy, or an extracorporeal operation) compared to radical surgery after 5 years of follow-up [8].

Two recent studies on ex vivo nephron-sparing surgery for renal carcinoma were published in 2014.

The first series included 9 patients. The absolute indications were organ saving and technical impossibility of renal tumor resection in situ. The mean duration of operation was 297.8 minutes, and the mean period of hypothermic ischemia consisted of 112.6 minutes. A postoperative followup (maximum 4 years) revealed that there is not noted dissemination of the tumor, and functional condition of the transplanted kidney was satisfactory [9].

The second series included 3 patients. Two patients had complex renal cell carcinoma, and 1 patient had bilateral large angiomyolipoma. All 3 patients did not have renal replacement therapy and currently live a good quality of life. According to the authors, the advantage of this procedure over renal replacement therapy is better quality of life and cost-effectiveness [10].

In this new era of minimal invasive surgery, laparoscopic renal harvest for autotransplantation provided an opportunity to decrease morbidity. Fabrizio et al. performed the first laparoscopic nephrectomy with open autotransplantation 
(kidney extraction was done through a periumbilical incision followed by a transplantation through a Gibson incision) [11].

Gill et al. described retroperitoneoscopic laparoscopic nephrectomy followed by open autotransplantation using a Gibson incision for both extraction and subsequent transplantation [12].

One of the largest series of laparoscopic nephrectomies for autotransplantation was reported by Tran et al. in 2015 including 52 patients with more than $90 \%$ success rate over a 6-year follow-up period [13].

Also, although a very challenging procedure, completely intracorporeal robot-assisted nephrectomy with RA is now a feasible approach to renal preservation after major ureteral injury [3].

Finally, a randomized study comparing RA to another approach like "bowel interposition" is necessary to determine the differences in benefits and risks associated with these procedures.

Analysis of values and changes in renal clearance revealed that the majority of patients had an improvement in renal function, with the exception of two patients with a postoperative clearance of $<60 \mathrm{ml} / \mathrm{min}(36.21$ and $41.5 \mathrm{ml} / \mathrm{min}$, resp.), knowing that these 2 patients had some degree of kidney failure before surgery (preoperative clearance of 60.5 and $59.5 \mathrm{ml} / \mathrm{min}$, resp.). This reflects the improvement in renal function and the rarity of delayed complications.

In our study, the patient with pelvic and bilateral ureteral tumors showed remission, without any recurrence on the annual scan even 7 years after the surgery, as well as for the patient with a solitary and an intrasinusal tumor who is disease free after 10 years of follow-up.

In this study, the relatively long follow-up (average of 55 months) empowers the study and explains RAs validity and effectiveness. However, a retrospective study like ours could be criticized. The limited number of patients enrolled, the one center-one surgeon experience are some of the limitations of this study.

\section{Conclusion}

Renal autotransplantation is a rare, safe, and effective surgical procedure for the treatment of complex urologic conditions. In some instances, it may be of great utility for kidney salvage in some carefully selected patients. Our center's experience in renal autotransplantation showed low complications rate, preserved kidney function, and no cancer recurrence on the early and late follow-up.

\section{Ethical Approval}

All procedures performed in studies involving human participants were in accordance with the ethical standards of the institutional and/or national research committee and with the 1964 Helsinki Declaration and its later amendments or comparable ethical standards.

\section{Consent}

Informed consent was obtained from all individual participants included in the study.

\section{Conflicts of Interest}

The authors declare that they have no conflicts of interest.

\section{Authors' Contributions}

Ali Bourgi performed project development and manuscript writing. Rana Aoun was involved in data collection. Elias Ayoub did manuscript writing. Maroun Moukarzel was responsible for data analysis and manuscript editing.

\section{References}

[1] R. H. Dean, P. W. Meacham, and F. A. Weaver, "Ex vivo renal artery reconstructions: indications and techniques," Journal of Vascular Surgery, vol. 4, no. 6, pp. 546-552, 1986.

[2] A. M. Meraney, I. S. Gill, J. H. Kaouk, M. Skacel, and G. T. Sung, "Second prize (Co-winner): laparoscopic renal autotransplantation," Journal of Endourology, vol. 15, no. 2, pp. 143-149, 2001.

[3] Z. N. Gordon, J. Angell, and R. Abaza, "Completely intracorporeal robotic renal autotransplantation," The Journal of Urology, vol. 192, no. 5, pp. 1516-1522, 2014.

[4] S. Pettersson, H. Brynger, C. Henriksson, S. L. Johansson, A. E. Nilson, and T. Ranch, "Treatment of urothelial tumors of the upper urinary tract by nephroureterectomy, renal autotransplantation, and pyelocystostomy," Cancer, vol. 54, no. 3 , pp. 379-386, 1984.

[5] S. Pettersson, H. Brynger, S. Johansson, and A. E. Nilson, "Extracorporeal surgery and autotransplantation for carcinoma of the pelvis and ureter," Scandinavian Journal of Urology and Nephrology, vol. 13, no. 1, pp. 89-93, 1979.

[6] S. Holmäng and S. L. Johansson, "Tumours of the ureter and renal pelvis treated with resection and renal autotransplantation: a study with up to 20 years of follow-up," BJU International, vol. 95, no. 9, pp. 1201-1205, 2005.

[7] C. W. Putnam, C. G. Halgrimson, D. P. Stables et al., "Ex vivo renal perfusion and autotransplantation in treatment of calculous disease or abdominal aortic aneurysm," Urology, vol. 5, no. 3, pp. 337-342, 1975.

[8] H. Zincke, D. E. Engen, K. M. Henning, and M. W. McDonald, "Treatment of renal cell carcinoma by in situ partial nephrectomy and extracorporeal operation with autotransplantation," Mayo Clinic Proceedings, vol. 60, no. 10, pp. 651-662, 1985.

[9] B. K. Komiakov, S. A. Zamiatnin, S. V. Popov, V. V. Shlomin, A. V. Tsygankov, and I. S. Gonchar, "Extracorporal surgical treatment of patients with renal cell carcinoma," Vestnik Khirurgii Imeni II Grekova, vol. 173, no. 4, pp. 53-56, 2013.

[10] G. P. Abraham, A. T. Siddaiah, K. Ramaswami, D. George, and K. Das, "Ex-vivo nephron-sparing surgery and autotransplantation for renal tumours: Revisited," Canadian Urological Association Journal, vol. 8, no. 9-10, p. E728, 2014.

[11] M. D. Fabrizio, L. R. Kavoussi, S. Jackman, D. Y. Chan, E. Tseng, and L. E. Ratner, "Laparoscopic nephrectomy for autotransplantation," Urology, vol. 55, no. 1, p. 145, 2000.

[12] I. S. Gill, R. G. Uzzo, M. G. Hobart, S. B. Streem, D. A. Goldfarb, and M. J. Noble, "Laparoscopic retroperitoneal live donor right nephrectomy for purposes of allotransplantation and autotransplantation," The Journal of Urology, vol. 164, no. 5, pp. 1500-1504, 2000.

[13] G. Tran, K. Ramaswamy, T. Chi, M. Meng, C. Freise, and M. L. Stoller, "Laparoscopic nephrectomy with autotransplantation: Safety, efficacy and long-term durability," Journal of Urology, vol. 194, no. 3, pp. 738-743, 2015. 


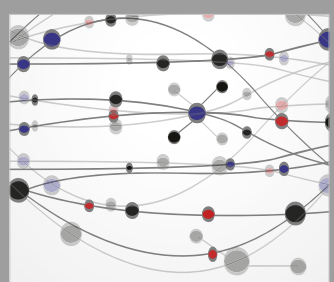

The Scientific World Journal
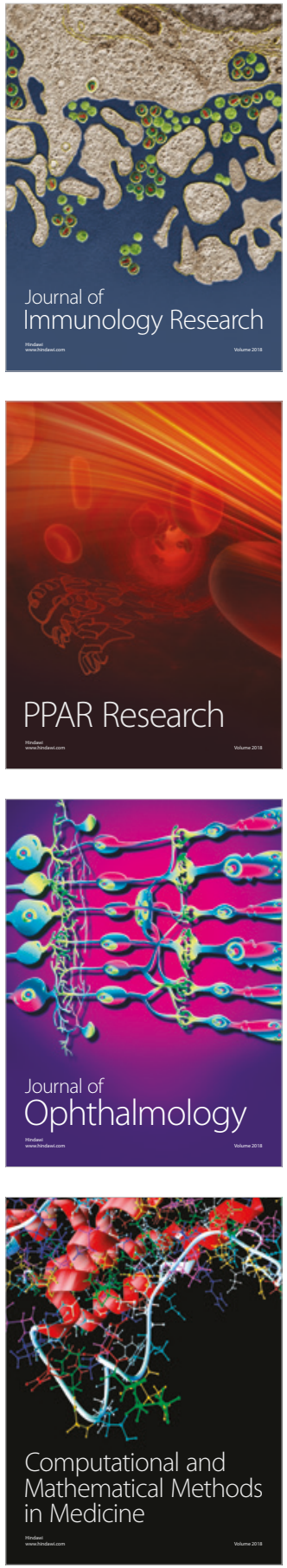

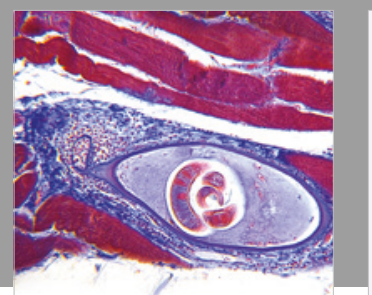

Gastroenterology Research and Practice

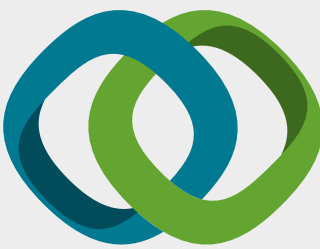

\section{Hindawi}

Submit your manuscripts at

www.hindawi.com
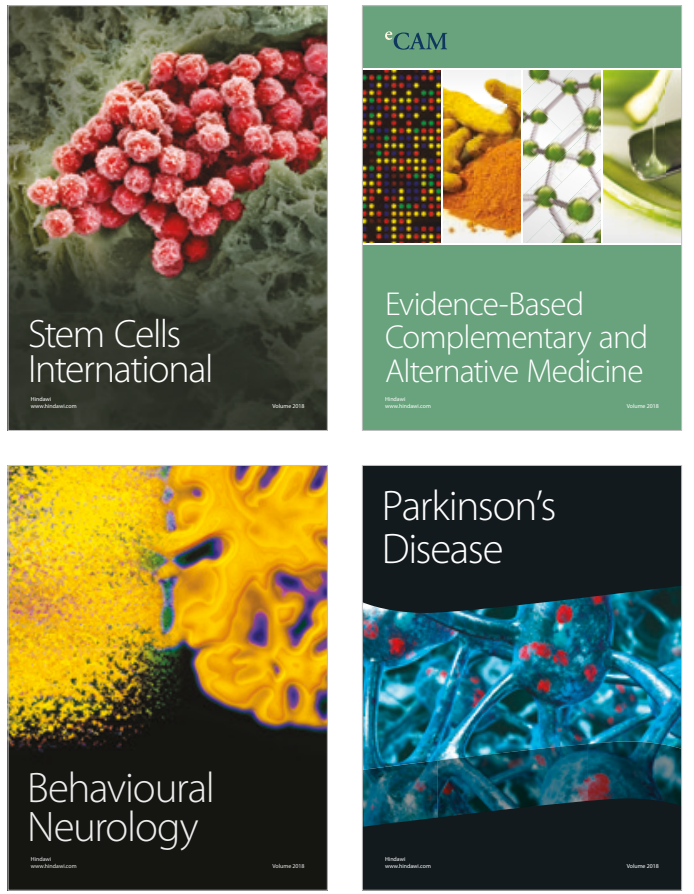

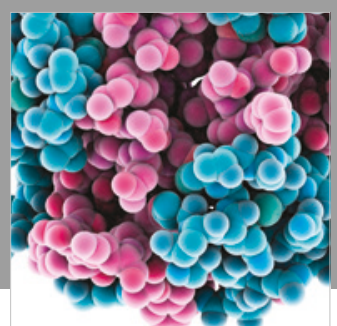

ournal of

Diabetes Research

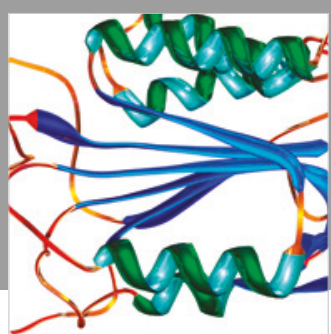

Disease Markers
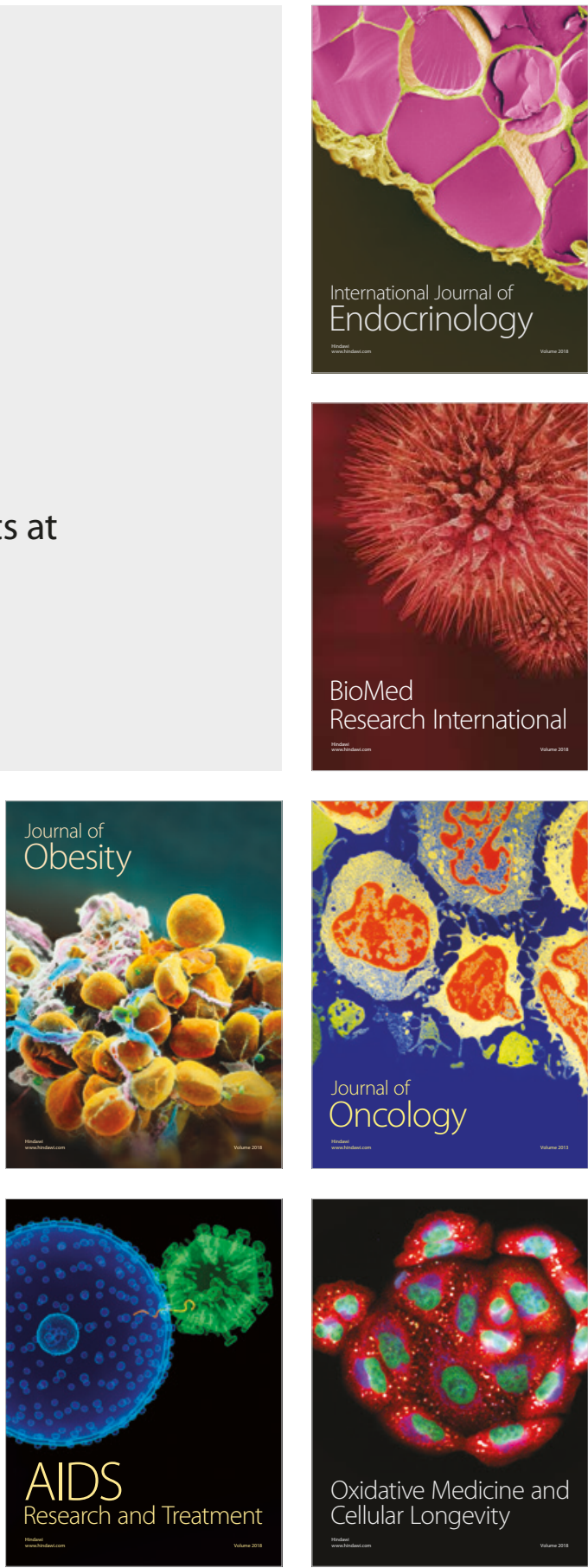